\title{
A QUANTITATIVE METHOD FOR ESTIMATING THE PERIODICITY OF DIATOMS
}

\author{
By Anwar Abdel Aleem, M.Sc., Ph.D. \\ (Farouk University, Alexandria) \\ From Queen Mary College, University of London
}

(Plate I and Text-fig. I)

\section{INTRODUCTION}

The method described below was evolved as a substitute for counting, which is unsatisfactory for epiphytic marine diatoms. It depends upon the estimation of the amount of diatom-silica associated with unit dry weight of the substratum. The sea-weed samples are first freed from sand particles and are then treated with strong nitric acid in the usual way. In order to convert the insoluble silica of the diatoms into a soluble form suitable for chemical estimation, the material is fused in a platinum crucible with a mixture of $\mathrm{K}_{2} \mathrm{CO}_{3}$ and $\mathrm{Na}_{2} \mathrm{CO}_{3}$ and the fused mass is dissolved in (silica-free) distilled water and filtered. The amount of silica in the filtrate is determined colorimetrically according to the method of Dienért and Wandenbulcke (cf. Atkins, 1926). The method is simple in practice and saves considerable time and labour. The full procedure is illustrated by reference to a study of the periodicity of Grammatophora marina (Lyngb.) Kütz. at Swanage, Dorset.

This species (Pl. I) is found all the year round on Cladophora rupestris in a pit in one of the reefs at Peverel Point, Swanage. In summer it is the only epiphytic diatom on the Cladophora, while in spring and autumn small numbers of other epiphytes (Cocconeis, Opephora, Rhoicosphenia) are present. In order to obtain a fairly representative picture of the abundance of Grammatophora at different times, samples of the Cladophora were collected monthly from a definite area in the pit, each including $3-4 \mathrm{~cm}$. of the apices of five to ten Cladophora tufts cut at random. The tufts are soaked in sea water to free them from sand particles and preserved in $4 \%$ formalin.

\section{Method of Estimation}

After soaking in several changes of distilled water, the sample is transferred to a small crucible and dried in an electric oven at $100^{\circ} \mathrm{C}$. for several hours; the crucible is then allowed to cool in a desiccator. When a constant weight has been attained, the contents of the crucible are boiled with concentrated nitric acid until all the organic matter is destroyed, as shown by the addition 
of a few crystals of potassium chromate. The remaining material is washed thoroughly with water, and subsequently repeatedly washed with alcohol or ether. After drying it is mixed with about twenty times its volume of $\mathrm{K}_{2} \mathrm{CO}_{3}$ and $\mathrm{Na}_{2} \mathrm{CO}_{3}$, in the proportions of $2: \mathrm{I}$, and the mixture is fused in a platinum crucible over a strong Bunsen flame for at least $20 \mathrm{~min}$., care being taken to avoid a smoky flame. The melting-point is lowered by using the two carbonates.

After fusion is complete, water from a tap is allowed to play on the hot crucible in order to prevent the contents from adhering to the sides. The fused mass is then dissolved in warm distilled water and the solution filtered. If fusion has been carried out properly, no appreciable residue remains. The filtrate is diluted to $50 \mathrm{ml}$. with distilled water and shaken. According to the concentration of silica present, $\mathrm{I}-5 \mathrm{ml}$. of this solution are pipetted into clean pyrex tubes, again diluted to $50 \mathrm{ml}$. and the amount of $\mathrm{SiO}_{2}$ in the final solution determined colorimetrically. For each determination $2 \mathrm{ml}$. of a $10 \%$ solution of ammonium molybdate and four drops of $50 \%$ (by volume) sulphuric acid are required. After adequate stirring an intense yellow colour appears within $2-5 \mathrm{~min}$. at $20-25^{\circ} \mathrm{C}$. and this colour is matched with a standard colour produced by a known concentration of silica. For this purpose a set of B.D.H. 'V.H.B.' tinometer disks was used. The matching of the colour was carried out in daylight in front of a north window. The yellow colour is produced only within a certain range of $\mathrm{pH}$ (the resulting mixture should be close to $\mathrm{pH}$ 2), and one more drop of acid may suppress it altogether. Phosphates and arsenates give the yellow colour only when present in large amounts, but the diatom does not contain them. Errors in the chemical estimation of the silica owing to incomplete fusion or to incomplete production of colour during the colorimetric tests are easily avoided. The same interval of time was always allowed to elapse between adding the reagents and carrying out the tests which were always performed at approximately the same temperature.

For computing the amount of $\mathrm{SiO}_{2}$ per gram dry weight of the Cladophora the following equation is used:

$$
x=\frac{50 e}{w}
$$

where $x$ is the unknown quantity (in $\mathrm{mg}$.) of silica found in I g. dry weight of Cladophora, $e$ the actual amount (in $\mathrm{mg}$.) of silica present in $\mathrm{I} \mathrm{ml}$. of the filtrate as estimated with the tintometer, and $w$ is the actual dry weight of the sample in grams. $w$ includes the dry weight both of the substratum and of the epiphyte, but since that of the latter is negligible in comparison with that of the former a correction was deemed unnecessary. If sand is present, the cleaned diatom-material is well shaken in water, the liquid allowed to stand until the sand has settled and the supernatant liquid containing the diatoms poured off and centrifuged. The sandy sediment is dried and weighed, and the weight subtracted from the initial dry weight of the sample. 
The results of a series of estimations are given in Table I.

TABle I. ABundance of GRAMMATOPHORA MARINA ON CLADOPHORA at Swanage, Expressed in mg. of $\mathrm{SiO}_{2}$ Per Gram of Dry Weight

$\begin{array}{cc}\text { Date } & \mathrm{SiO}_{2} \\ \text { I947 April } & 80 \cdot 0 \\ \text { May } & 58 \cdot 8 \\ \text { July } & \mathrm{I} \cdot 6 \\ \text { August } & \mathrm{I} 2 \cdot 7 \\ \text { September } & 26 \cdot 6 \\ \text { December } & 2 \mathrm{I} \cdot 7 \\ \text { I948 January } & 37 \cdot 8 \\ \text { February } & 88 \cdot \mathrm{I} \\ \text { March } & 34 \cdot 5\end{array}$

\section{Comparison with the Counting Method}

The accuracy of the method was tested by counting the individuals of Grammatophora present in the samples (Table II). The cleaned diatom material was diluted with a definite volume of water, depending upon the density of the sample. After thorough shaking, a ml. at a time of the suspension was pipetted into a counting cell, ruled into $\mathrm{I}$ and $\frac{1}{16} \mathrm{~mm}$. squares (corresponding to volumes of $\mathrm{I} \mathrm{mm} \cdot{ }^{3}$ and $\frac{1}{16} \mathrm{~mm} \cdot{ }^{3}$ respectively), and holding just $\mathrm{I} \mathrm{ml}$. when covered with a cover-glass. According to the density of the sample, counts were made either, under low power, of the number of frustules in a square millimetre or, under high power, of the number within the field of the microscope. The squares or fields were chosen at random, the number counted ranging between 4 and 88 . Half frustules were counted as such, although it was sometimes difficult, especially under low power to distinguish them from whole ones. After making the counts the contents of the cell were carefully washed back into the original suspension to be used for the fusion tests.

In computing the total number of frustules of Grammatophora per gram of dry weight of Cladophora in a sample the following formula was used

$$
n=\frac{n_{1} \times v \times \mathrm{IO}^{3}}{w},
$$

where $n$ is the total number per gram dry weight; $n_{1}$ is the average number of frustules in a cubic millimetre of the counting cell, $v$ the volume in $\mathrm{ml}$. of the diluted diatom-material and $w$ the actual dry weight in grams of the original Cladophora material. This gives the number of individuals of Grammatophora marina per gram dry weight of Cladophora in April 1947 as

approximately.

$$
\frac{193.6 \times 25 \times 10^{3}}{0.5}=9.68 \times 10^{6}
$$

The degree of abundance of Grammatophora marina in successive months, as determined by the two different methods, is shown graphically in Text-fig. I. 
The two graphs run almost exactly parallel and show clearly that G. marina has a pronounced maximum in early spring and a secondary one in autumn. Comparing the graphs and bearing in mind that they are drawn to different scales, that based on the silica content of the samples is relatively flat, the range of values being comparatively low. The amount of silica in the diatom material at the time of maximum abundance in February 1948 is only about seven times that found at the time of the minimum in August 1947, while the

TABLe II. Computation of the Periodicity of GRAMMATOPHORA IN THE GramMatophora-CLADOPHORA COMMUNity at SWANAGE By the Counting Method

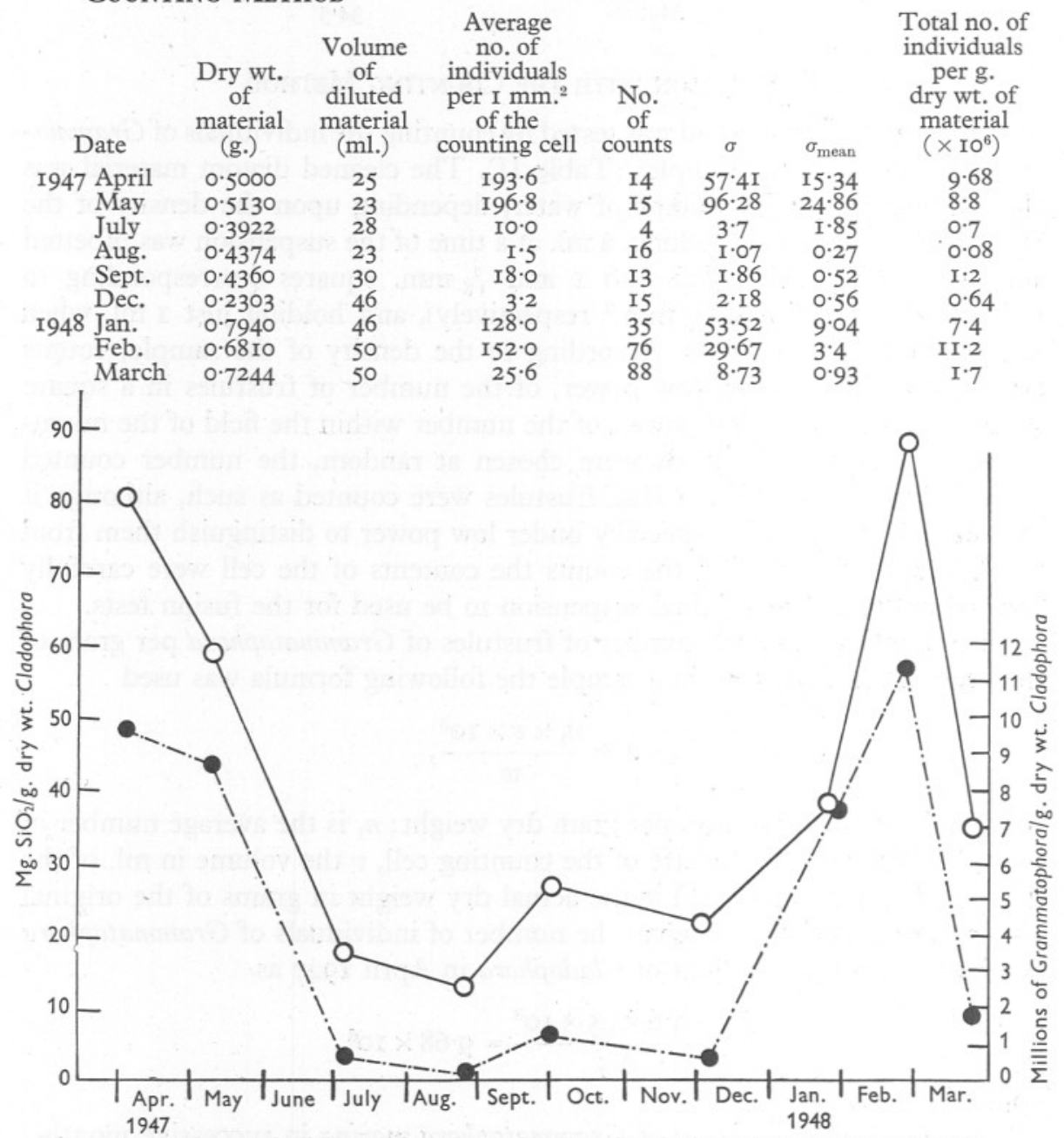

Text-fig. I. Periodicity of Grammatophora marina during 1947-48, as computed by: (a) the silica-content method $(-)$; $(b)$ the counting method $(-\cdot-)$. 


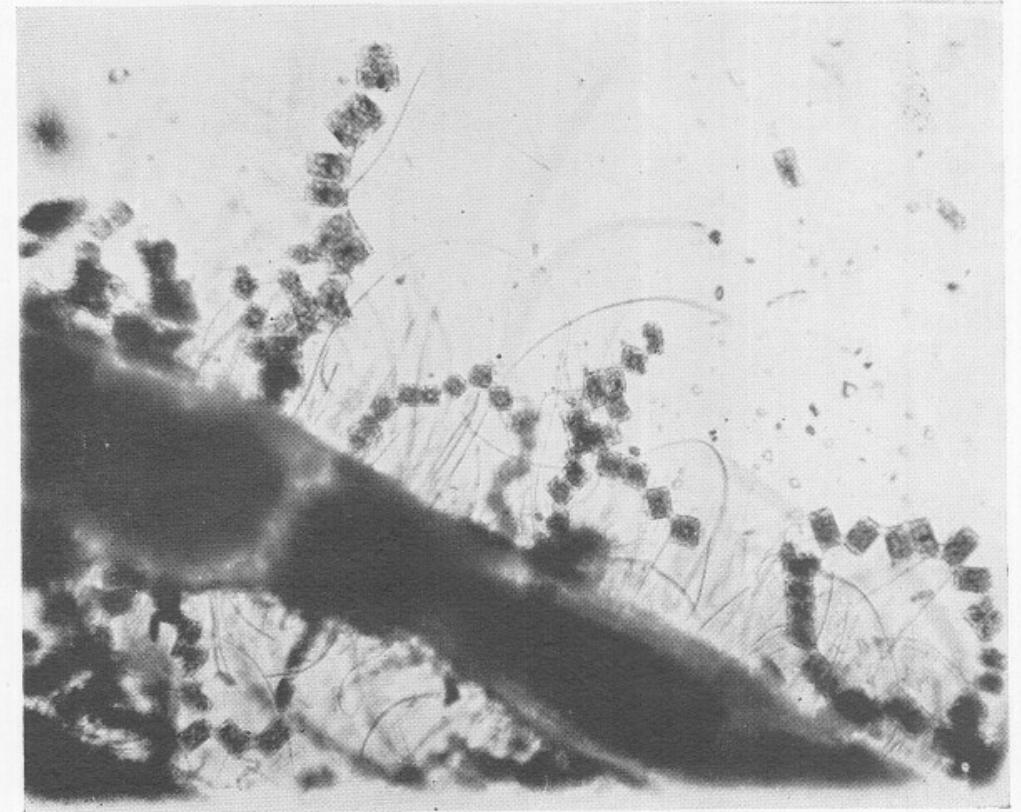

Fig. I.

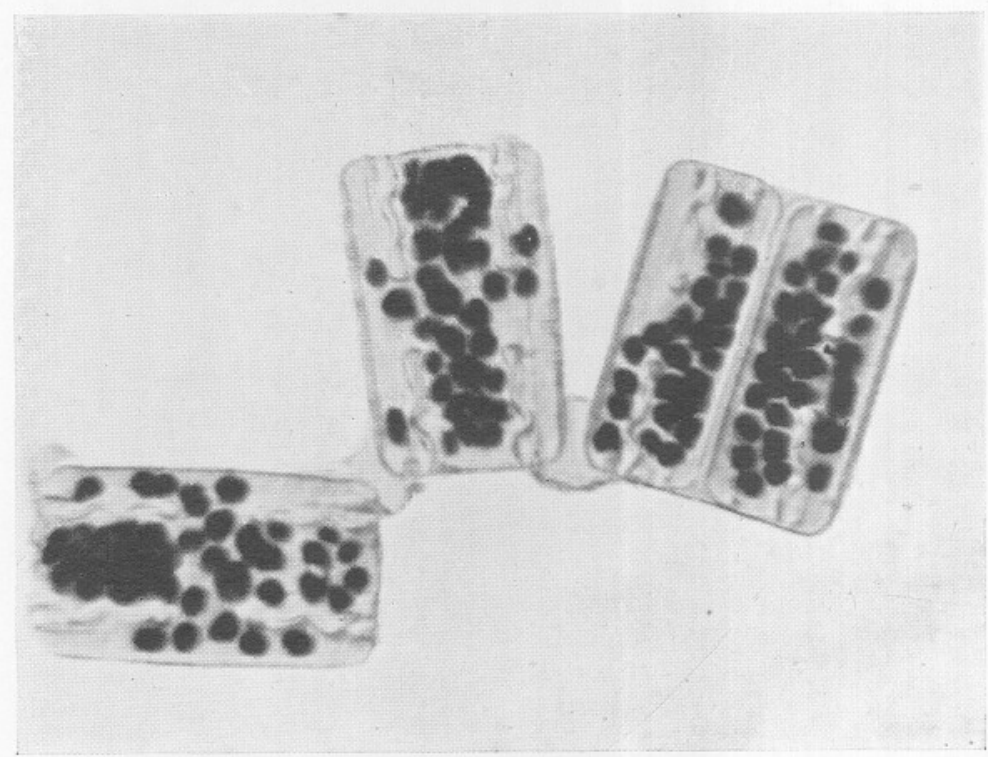

Fig. 2 
counting method shows the ratio of the numbers of frustules on these two dates to be about I00:I. The discrepancy is due to the fact that the amount of silica is not actually proportional to the numbers of frustules, but to their total surface area. ${ }^{1}$ At certain times, and especially when there is abundant multiplication, the individuals may be very small, a considerable number being only about one-quarter of the usual length. The occasional inclusion of a half as a whole frustule during counting is another cause for the discrepancy between the results of the two methods.

\section{Discussion}

The ability of a diatom to assimilate silica from the medium and produce new frustules during multiplication affords a measure of its rate of growth. The total amount of growth at a given time will be represented by the quantity of silica present. The silica method is comparable to the pigment-extract method used by Harvey (1934), in which the amount of pigment extracted from a known volume of sea water is taken to indicate the quantity of phytoplankton present. The silica method, on the other hand, can be regarded as specific for diatoms.

The amount of silica in the diatom material can be expressed in terms of unit weight, unit area or unit volume of the medium or substratum. The method can therefore be used for determining the periodicity of planktonic, lithophytic (e.g. Schizonema) or epiphytic diatoms. The samples must not, however, contain other organisms having a siliceous envelope (e.g. Silicoflagellates).

The method is open to the criticism that the degree of silicifaction of the frustules of a given species of diatoms may not be the same at all times of the year or in individuals of different sizes. There is at present no accurate information on this matter, but it seems probable that the amount of silicification is constant in most species, judging from observations made at different times.

I am indebted to Prof. F. E. Fritsch, F.R.S., and to Dr W. R. G. Atkins, F.R.S., for valuable advice and criticism, and to Dr F. M. Haines for reading the manuscript.

\section{REFERENCES}

Atrins, W. R. G., I926. Seasonal changes in the silica content of natural waters in relation to the phytoplankton. Fourn. Mar. Biol. Assoc., Vol. xIv, pp. 89-99.

Harvey, H. W., I934. Measurement of phytoplankton population. Fourn. Mar. Biol. Assoc., Vol. xIX, pp. 76I-73.

\section{EXPLANATION OF PLATE I}

Fig. I. Photomicrograph of the Cladophora-Grammatophora community.

Fig. 2. Part of the colony of Grammatophora marina shown above, enlarged.

${ }^{1}$ It is assumed that the frustules are uniformly silicified and that the thickness of the valves is the same whatever the size. 